\title{
24 \\ HUMAN SMUGGLING, GENDER AND LABOUR CIRCULATION IN THE GLOBAL SOUTH
}

\author{
Priya Deshingkar
}

\section{Introduction}

Irregular $^{1}$ migration $^{2}$ facilitation, or human smuggling, has been made hyper-visible in the context of tightening border controls in Europe, North America and other prosperous parts of the world. The focus of this discourse is predominantly on South-North clandestine journeys, especially from Africa in the case of Europe (ENACT 2020), based on data on interceptions in the Mediterranean. This narrative has eclipsed South-South human smuggling, which is equally if not more significant in terms of the numbers it involves; however, research on it remains thin (see for example Ayalew et al. (2018), Lindquist (2012), Lindquist et al. (2012) and Afsar (2009)). South-South smuggling may involve being smuggled across a border between two neighbouring countries or to a distant country. Every day, millions of irregular border crossings take place between countries in the Global South that share borders, such as Myanmar and Thailand or Bangladesh and India.

There are also clear "corridors" of smuggling among non-contiguous countries, some separated by considerable distances and on separate continents, such as Bangladesh and South Africa (Momen unpublished), Myanmar and Malaysia (Deshingkar et al., 2019), and Ethiopia and Saudi Arabia (Adugna et al., 2021). These corridors have evolved with the emergence of relatively lucrative work options in manufacturing and processing, care work and a variety of jobs in cities. Corridors are strengthened as transnational networks of migration are established, leading to further migration to particular destinations where migrants can draw on the support of their networks in integrating and making a life for themselves.

Irregularity in migration encompasses a range of scenarios - overstaying visas (Momen and Deshingkar et al., 2019), delinking from tied work permits (Deshingkar et al., 2019; Jureidini, 2017), irregular border crossings (Ayalew et al., 2018; Triandafyllidou 2020; Triandafyllidou and Bartolini, 2020), rejected asylum seekers and the children of undocumented parents (Triandafyllidou and Bartolini, 2020). Here we are concerned mainly with the actors and processes involved in irregular border crossings which involve entering a country without complying with the necessary requirements for legal entry, such as possessing a valid visa, work permit or health certificate, or entering at points not designated as ports of entry.

Smuggling processes in West Africa are deeply connected to the geopolitics of migration management, as many of the policies that shape it are driven by interests in the North. In South 
and South East Asia, they are shaped by the immigration regimes and labour circulation policies in receiving countries, but in different ways, as discussed in the following pages.

In order to provide a thick account of smuggling operations on the ground, only three contrasting countries are discussed in detail below, namely Ghana, Bangladesh and Myanmar. ${ }^{3}$ They share similarities - all have more than $70 \%$ of the population depending on agriculture and between $68 \%$ and $77 \%$ living in rural areas. ${ }^{4}$ They also have key differences which provide fertile opportunities for exploring how the intersection between culture, the geopolitics of migration control, globalised patterns of labour circulation, and the state, shape human smuggling patterns.

In the three countries under consideration, migration for low-paid and informal work is most common and as such, the focus of this chapter is on smuggling as it relates to the broad category of labour migration. While labour circulation from poor countries towards rich countries has now become an established part of key sectors including care work and construction work, restrictions on mobility are also mounting at the same time. For many, being smuggled across borders is often the only realistic option to access remunerative work opportunities. Even this, though, has become difficult and expensive since the act of human smuggling itself was criminalised with the launch of the UN Convention against Transnational Organized Crime in 2000 and its Protocol against the Smuggling of Migrants by Land, Sea and Air, which came into force in 2004. Its sister Protocol to Prevent, Suppress and Punish Trafficking in Persons Especially Women and Children was introduced at the same time. Smuggling always involves crossing a border and may be voluntary, whereas trafficking can occur in the same country and always involves the exploitation of a person for profit. $^{5}$

Southern countries in irregular migration "hot spots" have taken a range of steps to implement the Protocol and limit human smuggling, often with the aid of rich countries in the North that seek to contain migrants before they reach their shores. These measures include imprisoning and fining smugglers, awareness creation campaigns about the costs and risks of irregular migration and smuggling, and physical policing along known routes (Ayalew Mengiste, 2018; Ayalew et al., 2018; Carling, 2016; Sanchez, 2017). The justification for the increased policing of smuggling activities is to protect migrants, who are characterised as gullible and vulnerable, against smugglers, who are constructed as unscrupulous criminals and traders in human beings (Adugna et al., 2019; Sanchez, 2018). The process of smuggling is constructed in this imagination as beginning with an unsuspecting migrant entering the process voluntarily, only to be subjected to physical torture, execution and extortion further along the journey (Aronowitz, 2001). These messages are repeatedly reinforced through international media agencies such as AFP and Reuters (Adugna et al., 2021). While such outcomes are seen in a few cases, growing empirical evidence shows they are not representative of the experience of all migrants who use the services of smugglers.

\section{Smuggling and gendered circuits of labour circulation}

The extant literature indicates that there are often diverse infrastructures of human smuggling in the same geographical location for different kinds of destinations, occupations, and often quite separate infrastructures for men and women. For example, there are separate smuggling networks for feminised occupations and for those that are typically the reserve of men: in Ghana (Awumbila et al., 2019b, 2019a); Bangladesh (Abrar et al., 2017; Afsar, 2009; Rahman, 2020); Indonesia (Lindquist, 2012); and Myanmar (Franck et al., 2018).

Gender plays out in other ways in landscapes of smuggling. Women in patriarchal societies are subjected to additional barriers to mobility as they are seen as the weaker sex in need of 
protection, especially if they choose to migrate with the help of a smuggler. Here the UN Protocol on Human Trafficking with its explicit emphasis on 'women and children' is often invoked, ostensibly to protect women who are regarded as more vulnerable to abuse. Developing country governments are under intense pressure to comply with this international agenda through the influential US government's Trafficking in Persons (TIP) report (Palmary and de Gruchy, 2016).

There are also moral anxieties in many cultures about the sexual encounters that female migrants may have which pose a threat to their purity and the honour of the family. Traditional notions of masculinity in many societies construct the risks and dangers of migration experienced by men as strengthening of their character and making them into brave adult men. The opposite is true in these discourses on female migration, as women are seen as inherently more vulnerable and in need of constant surveillance, accompaniment and protection by men or the state (Deshingkar, 2021; Huijsmans, 2014; Platt et al., 2018) Consequently, female migrants have been subjected to migration bans in several countries - Ethiopia, Ghana, Nigeria, Myanmar, Bangladesh and Indonesia. This includes bans on certain kinds of feminised migration and low-paid work or bans on migration to certain destinations or both, some of which are discussed under the case studies below.

A deeper look at the intersections between human smuggling, global restrictions on mobility, immigration regimes and particular gendered occupations, yields important insights into how the state, smuggling networks, and employers in destination countries relate to each other. The analysis in the remainder of the chapter unpicks the dynamics of smuggling related to construction work and domestic work that are two of the most accessible occupations for migrants all over the world. Both are highly gendered occupations due to cultural notions and gendered stereotypes in both sending and receiving countries about the inherent capabilities of men and women and the work that is appropriate for them (Deshingkar and Zeitlyn, 2015; Zeitlyn et al., 2014). Domestic work is feminised and employs mainly women along certain migration corridors such as Ethiopia to Saudi Arabia and Sri Lanka to the Middle East (Fernandez, 2019; Gamburd, 2000). Additionally, domestic work is also racialised, wherein women from certain nationalities and ethnic groups are constructed as suited to servitude in the home based on their appearance and skin colour (Anderson and Anderson, 2000). Domestic and care work is important for female migrants with few formal qualifications. ILO estimates suggest that there are roughly 67 million domestic workers over the age of 15 worldwide, $80 \%$ of whom are women. Migrants are heavily represented in "global care chains," of domestic and care work with workers drawn mainly from poorer countries in the Global South (Parreñas, 2015; Yeates, 2012), into rich countries where more women are entering the workforce and the social reproduction of the family is passed on to domestic workers (Fong et al., 2020). Construction work is an accessible source of employment for male migrants (BWI, 2006), employing nearly 110 million people worldwide (ILO, 2001). Globally, the construction sector is heavily dependent on migrant labour (Buckley et al., 2016) and it is also a sector where irregular migrants are concentrated.

While the demand for migrant construction and domestic workers has grown, immigration regimes in receiving countries have become more exclusionary with complicated bureaucratic processes that are difficult for those who are located in remote locations away from government offices and the numerous agencies that provide health certificates and identity documents. Smugglers have become more important in migration for both occupations, for example, for the migration of domestic workers from Ethiopia to the Middle East (Fernandez, 2013) which is an important destination for migrants smuggled in for domestic work (Mahdavi, 2013). Similarly, Large numbers of Rohingya and other impoverished or persecuted people are 
smuggled into Malaysia for work in a range of informal labouring jobs, including construction (Wahab, 2018).

There are important differences in the way that smuggling for construction work and domestic work are organised; this depends on the policy context in both sending and receiving countries, the economic circumstances of the family, gendered policies, and norms within the family and wider society. Entangled with these structural factors are processes related to the financing of smuggling and the materialities of travel such as documents and transport vehicles.

\section{Not just at the border}

A key observation of this chapter is that human smuggling cannot be seen as a process that happens only at the border. Rather, it is shaped by a variety of spatially dispersed actors who fulfil different but complementary functions. This is especially characteristic of brokerage and smuggling, which are linked to placement at destination. In such instances, there is usually a continuum from the first point of contact between a migrant and a local broker to the end destination which is facilitated by interconnected intermediaries, including the actual border smugglers (Awumbila et al., 2019b; Deshingkar et al., 2019). Village level brokers in the migrant's own community may have established relations with recruitment agents in towns and cities who in turn are linked to travel operators, passport authorities, passport photo units, health testing centres, immigration officials and border police, and smugglers at the border, then finally placement agencies in the destination country. However, this is not the case for all forms of human smuggling and in some corridors where policing is intense, there is no discernible chain or network. Here smugglers and other intermediaries may come together more opportunistically as they have to navigate new controls and chart different pathways to overcome those. An example of this is human smuggling through Niger, where new and different smuggling routes around Agadez, an important hub for irregular migration in West Africa (Molenaar, 2017), are in a constant state of flux (Bredeloup and Pliez, 2011). A similar situation is seen in clandestine journeys between Ethiopia and Saudi Arabia, where smugglers are exploring new routes and linking up with new intermediaries all the time (Adugna et al., 2021).

In both kinds of scenarios, the village-level broker is often a key figure in remote and poorly connected societies, as they are critical for brokering contacts with the outside world and providing up-to-date intelligence on the best destination, modes of transport, official procedures and the required documentation. Brokers are either ex-migrants belonging to the same community or people with connections, knowledge of the outside world and the ability to communicate across different worlds and social rules (Abrar et al., 2017; Lindquist, 2012). Such is the cultural and linguistic divide between migrants and city-based officials and bureaucrats, that a broker is needed to interpret and communicate between the two parties. Brokers are also well connected beyond the villages that they operate in and are able to access key personnel and negotiate on behalf of the migrant to obtain documents and permissions.

Therefore, in order to understand the workings of human smuggling and the ways in which it shapes migration and labour markets, it is important to consider it in its entirety, and not just at the border. Smugglers can be conceptualised as one part of the broader infrastructure that facilitates irregular migration. Xiang and Lindquist's (2012) concept of the "infrastructures of migration" that emerged from their research on low-skilled migration from China and Indonesia examines the interconnected actors, technologies and institutions that together facilitate mobility, offers a useful framework of analysis. They argue that all of these components must be considered together with intersectionality as an operational logic to understand how they work together to make migration happen. The concept of migration infrastructures lends 
itself well to analysing human smuggling and irregular migration for low-paid occupations as it dwells on both the social aspects of human smuggling as well as is materialities, including documents, physical barriers at border crossings, makeshift accommodation structures, boats, desert vehicles and mobile phones. It provides the tools to interrogate how gender, immigration regimes, transport networks and the structure of employment intersect in different ways. I use it below to reveal the everyday manifestations of globalised labour circulation that depend on cheap foreign labour and the range of actors, and institutions that mediate it.

\section{A socially embedded process}

While considering the breadth of different actors and institutions involved in smuggling, it is also important to note that smuggling processes are deeply rooted within communities at points of origin and transit. These communities are comprised of actors with diverse interests whose search for work and business and social relations with migrants and smugglers continuously shapes and constitutes the spaces of brokerage and smuggling (Adugna et al., 2019; Bredeloup and Pliez, 2011; Deshingkar, 2021; Huijsmans, 2014). In poor communities with few sources of paid work, smuggling offers a critical source of income, albeit a modest one. These kickbacks from smuggling and the visible improvement in the standard of living of migrants' families has earned smugglers a reputation akin to that of heroes (Adugna et al., 2019). In fact, smugglers are able to operate precisely because local communities endorse their operations and perceive them as bringing benefits to everyone and not just the migrants and their families. In southern Ethiopia, where irregular migration to South Africa is widespread, those who facilitate it are called Berri Kefach or door openers (Adugna et al., 2019). These findings are corroborated in the wider literature; extended immersive research by Osella (Osella, 2014) among migrant communities in Kerala travelling to the Gulf, as well as research by Akesson and Alpes in Cape Verde and Cameroon (Åkesson and Alpes, 2019; Alpes, 2017) juxtapose the perceptions of local communities of brokers as critical to realising their migration project, notwithstanding their criminalisation by the state. Such narratives of smugglers being benefactors should not detract from the extremely high risk faced by migrants embarking on long and dangerous clandestine journeys, such as over-land crossings through the Sahara. The likelihood of coming to serious harm is very real; whether and to what extent they are able to escape and overcome adverse experiences to achieve their ultimate goal depends on a host of factors that are unpicked through empirical evidence of smuggling in the three countries under consideration.

Against this backdrop, the chapter draws attention to two implications of human smuggling. First, it shows how human smuggling and irregular migrants are critical to sustaining circuits of labour circulation of cheap and disposable workers. Heavily restricted immigration regimes such as the Kafala system in the Middle East ${ }^{6}$ create ideal conditions for human smuggling and irregularity. In turn, the irregular status of migrants allows employers and placement agencies to exploit them, with fewer obligations to protect their rights. Migrant construction workers and domestic workers are thus placed in a hyperprecarious situation (Lewis et al., 2015) that governments in receiving countries are complicit in producing. Second, the examples discussed below illustrate that human smuggling can open up opportunities for people from poor and marginalised backgrounds by enabling them to access work that holds the potential for making life-changing investments back home. The objective of the chapter is to draw attention to the complexity of the phenomenon and provide a nuanced understanding of South-South human smuggling. The three country cases are presented next to highlight these differences. 


\section{Ghana}

Ghana has a long history of migration within the country and internationally (Akyeampong, 2000 ) and is now an important source country for irregular migrants in the Libyan construction industry (Kandilige and Hamidou, 2011). Migration to Libya began in the 1990s when Gaddafi actively wooed sub-Saharan migrants (Bredeloup and Pliez, 2011). In recent years the country has been less welcoming to migrants both because of growing anti-migration sentiment in the context of a deteriorating economy and also introduction of the EU-Libya Migration treaty which sought to limit migration into Europe and targeted West African migrants in particular (Tonah and Codjoe, 2020).

Libya is the chosen destination here, not because migrants are unable to travel to Europe but because the Libyan labour market offers relatively high earning opportunities, albeit full of risk and uncertainty. In the current geopolitical context of ever-increasing controls on mobility and shrinking opportunities for legal migration, being smuggled across several countries northwards towards Libya has become the norm (Awumbila et al., 2019b; Kandilige and Hamidou, 2019). Nkoranza in the Brong Ahafo region and the border towns of Bawku and Tamale in Northern Ghana and are key points of origin and crossing the border out of Ghana. Policy barriers to movement within West Africa combined with differences in currency and language among the countries make the assistance of smugglers critical, especially for organising long and treacherous journeys through the Sahara Desert, traversing several international borders.

This kind of high risk and dangerous migration is male dominated due to cultural norms and the place of migration in men's strategies to achieve wealth and prove their manhood. Male migration in Ghanaian society is embedded in traditional notions of masculinity; among young men it is inextricably linked to establishing themselves as 'independent, respectable and marriageable adults' (Kleist, 2017), while older men migrate to provide for their families and invest in land, housing and business (Awumbila et al., 2019b). International migrants or "Borgas" as they are known locally, are admired for their material wealth, lifestyle, and ability to support their family members (Kleist, 2017). Women's migration from this area for low-paid work to Libya is rare, as there are fewer manual jobs for women there, so it is assumed that any woman who migrates, for sex work; this stigmatisation impacts on her marriage chances back home (Darkwah et al., 2019). However, migration for domestic work to the Gulf states is on the rise from the capital city and its adjacent areas, as discussed below.

Nkoranza in Brong Ahafo is well known for its "connection men" who facilitate journeys to Libya as well as European destinations. They have connections in the transit towns of Bawku, Niamey, and Agadez whom they can recommend to the migrant or communicate with themselves if they deem it necessary. Connection men are preferred over legal channels because they are more accessible, deals with them can be struck up immediately without paperwork, and they offer the promise of delivering the migrant to Libya, as they have successfully organised numerous irregular crossings before. They offer a package at one service point: organising the trip through the desert; and obtaining passports and other documents without the need for official documents (Awumbila et al., 2019b; Lucht, 2013).

Returned and deported migrants recount harrowing details of journeys by road in a variety of overcrowded trucks, buses and pick up vans through Togo, Benin and Niger all the way up to Libya with the constant threat of being robbed, beaten and imprisoned or deported (Awumbila et al., 2019b).

A majority of male migrants who have been smuggled into Libya are employed in construction as well as other artisanal jobs, such as electricians and tailors (Tonah and Codjoe, 2020). Irregular migrants are preferred by small construction companies as they are cheaper to 
employ and more exploitable. Propelling this stream of irregular migration from rural Ghana was the desire to earn better among those who wanted more than agriculture could offer. The average cost of being smuggled into Libya in 2017 was around $\$ 6000$, and only those who could sell assets or borrow to finance the journey were able to migrate (Awumbila and Torvikeh, 2018; Teye et al., 2015). The high cost did not guarantee a smooth journey and most migrants recounted horrific accounts being robbed at gunpoint, seeing other migrants die on the way, and being beaten. The suffering did not end after entering Libya either; migrants recalled being randomly robbed by militias, and being kept in overcrowded illegal detention without clean drinking water or washing facilities until they were bailed out by a relative. Deportations were common where migrants lost everything, including their money and their reputation as successful men back home.

Libya, nonetheless, continued to be seen as a place where money could be made, and lives could be transformed. Returned migrants mentioned that if they managed to stay in Libya without being deported for two years, the earnings from construction work there would be more than they would earn back home in a decade and this allowed them to buy land, pay off debts and invest in small businesses. This was one reason for deported and returned migrants planning to remigrate to Libya once again. Another reason for men's remigration was to rescue their masculine identity of being family providers (Kleist, 2017).

For women, the routes to international migration and finding work in achieving such transformations are more complex. Ghana passed the 2005 Human Trafficking Act, amended in 2009, which criminalized sex and labour trafficking. Well-known brokers, trusted by communities, were arrested and imprisoned, leaving smuggling to less accountable fly by night operators (Deshingkar, 2018). Women aspiring to leave the country for low paid work in the Gulf must negotiate social structures at home to depart culturally ascribed life trajectories and structural factors at destination. These propel them towards certain feminised niches in the job market. Domestic work is an important avenue of employment for women and girls from poor backgrounds within Ghana; some may attempt international migration after gaining experience and saving enough to pay brokers.

Ghana is a relatively new entrant to the globalised circuits of labour that supply domestic and care workers to the Gulf countries. Ghanaians are now found in significant numbers in the UAE, Kuwait and Saudi Arabia together with workers from Ethiopia, Eritrea, Uganda, Kenya and Nigeria (Bisong, 2021). The number of Ghanaians seems to be on the rise and Saudi Arabia is the most popular destination (GAATW, undated) despite a ban on migration to the Gulf countries for domestic work in 2017. The ban was introduced to safeguard women against abuse after there were reports of abuse at the hands of brokers and employers (GAATW, undated).

While the ban halted the operations of licensed recruitment agencies, informal brokers and smugglers continued to operate and facilitated the migration of Ghanaians to the Gulf States through neighbouring countries (Deshingkar, 2018). The Accra-Tema area has become a hub for the recruitment and irregular migration of women to the Gulf and is known for connection men who have "successfully" sent women abroad. Prior to the ban the Ghanaian Labour Department arranged exit permits, pre-departure preparation and monitoring of workers after they had reached their destination. During the ban, none of these processes was followed, as most of the migration for domestic work to the Gulf was irregular (GAATW, undated).

Awumbila's (Awumbila et al., 2019b) study was able to reach a very small number of female returnees from the Gulf who had all come back before expected, as they found the work too demanding and the behaviour of the employers unacceptable. Both in this study and the research reported in the GAATW report, it was mainly women who were not married or 
supported by a husband who decided to migrate. It is not clear how many of the women who migrate from Ghana are remaining in the Gulf for extended periods of time as research is scarce, but the numbers quoted by GAATW suggest that more and more women are deciding to migrate there: smugglers are key to enabling them to fulfil their aspirations.

\section{Myanmar}

Myanmar is now the largest exporter of low-skilled labour in Southeast Asia (Testaverde et al., 2017). Decades of chronic underdevelopment and conflict, as well as the long border with Thailand, have created opportunities for human smuggling and irregular migration. There are an estimated five million Myanmar migrants in Thailand, with many entering through migrant smugglers (Carden, 2014). In fact, irregular migrants are a critical component of the profit model of Thai firms that is based on cheap and exploitable labour (Pearson and Kusakabe, 2012).

A significant proportion of this cheap labour is from the bordering states of Mon and Kayin (Deshingkar et al., 2019). For young men and women, migration to Thailand has become an important way of repaying family debts and supporting younger siblings.

Notwithstanding the proximity of Mon and Kayin to Thailand, the journey is nearly always undertaken with the help of transport providers known as "Carry" who smuggle them across the border. There are several reasons for this, includinghigh costs and complicated and time-consuming migrant registration processes in Thailand (Buckley et al., 2016). In addition, migrants prefer to remain irregular, as this gives them more options for staying in the country longer and switching employers (Deshingkar et al., 2019). Another reason is that migrants say they feel better protected by a smuggler, who handles all the bribes and complicated transport arrangements along the way (Deshingkar et al., 2019). It is seen that even highly experienced migrants who have been migrating to Thailand for several years use the services of Carry to enter Thailand either through the dedicated ports of the Three Pagoda pass or along other points in the porous border. On average, migrants from Mon paid 30,000 kyat in 2018 ( $1 \mathrm{USD}=1000 \mathrm{kyat})$ to village-level brokers who linked with their Carry to cross the border to Thailand and then another 1,200 baht ( 1 USD $=30$ Thai baht) for onward journeys that were paid to local transporters and informal placement agencies. These costs were usually financed through borrowing from relatives and paid off gradually after finding work. Nearly all crossed the border illegally without any documents, but then regularised their status after a period of time. In fact, despite a series of measures introduced by the Thai government to control irregular migration and the bilateral Memorandum of Understanding, nearly all migration from Myanmar to Thailand is irregular (Balcaite, 2019; Thu and Ko, 2015).

The cultural context of irregular migration and human smuggling for construction work is altogether different in Myanmar compared with Bangladesh and Ghana. Those migrating from Mon and Kayin are young, often in their early 20s, with low levels of education and belonging to very poor families (Deshingkar et al., 2019). Masculinities and femininities play out in this smuggling landscape too, but in a less polarised way, perhaps because the migration is over a shorter distance and involves fewer risks compared to trans-Sahara migration in West Africa. While women are still socially constructed as the weaker sex and in need of protection and their identities constructed as daughters, wives and mothers, changing attitudes to migration have meant there are now options for them to travel abroad and work in a sector that is male dominated in other parts of the world. Female migrant construction workers were mainly from the poorest families without older male siblings who could migrate to support the family. Many women in the study by (Deshingkar et al., 2019) provided culturally accepted reasons for their 
migration and justified it as a way of fulfilling their duty to provide for their parents in their old age, their younger sibling's education, or monk ceremonies.

Kayin is known for the migration of domestic workers to Thailand, and this pattern has resulted from social networks and established migration streams. As was seen in the case of Mon construction workers, the prevalence of informal brokers and Carry was widespread in this kind of migration. The journeys of female domestic workers were much longer and far more hazardous than those of male construction workers because most of them were being delivered all the way to the homes of informal brokers in the heart of Bangkok. One respondent in Deshingkar et al. (2019) study said the $500 \mathrm{~km}$ journey from her home to Bangkok took ten days with several stops in hideouts along the way. Although none of the women reported sexual harassment or abuse by the brokers, deception and physical confinement was common.

While the exploitation and deceit experienced by migrants travelling with the assistance of a Carry have been documented by Meyer et al. (2015), there is insufficient discussion in the literature on the other aspects of the relationship between migrants and smugglers. Those travelling to construction sites just across the border in Thailand were unequivocal in saying that migrating with Carry was the easiest and surest way of reaching their destination, if a bit expensive. Many said they felt protected by the brokers and Carry, in contrast to the policy discourse on smugglers, which portrays them as ruthless criminals (Deshingkar et al., 2019). Women migrating for domestic work also felt it was best to migrate with the help of known smugglers, in spite of the difficulties they experienced, as they understood that the steps they took were necessary to evade detection at the border. They preferred the Carry to handle everything, paying border officials and other brokers, instead of negotiating their passage with unknown people all by themselves.

The poorest families, who were not able to finance the migration of their daughters, entered debt-migration, which is widespread in domestic work across Asia (Deshingkar, 2021; Platt et al., 2017). In Myanmar it was encountered more frequently in the poorest families where aspiring migrants could not mobilise capital to finance the migration (Griffiths and Ito, 2016). The costs of migration (transport, obtaining papers, permits and visas) and job placement are borne by the broker and/or employer, and the migrant repays through salary deductions over a period ranging from four months to a year. The interviews carried out by (Deshingkar et al., 2019) suggested that migrants were remitting substantial amounts of money back to their families; this corroborates the findings of (Kusakabe and Pearson, 2015).

\section{Bangladesh}

There are multiple circuits of transnational irregular migration originating in Bangladesh, with smuggling networks extending across the globe all the way to Libya in the West (Siddiqui and Bhuiyan, 2013) and Malaysia in the east (Rahman, 2020). Bangladesh has emerged as an important source country for irregular migrants who are employed in construction labour in the Gulf countries, as well as rich countries in Southeast Asia. Such workers are critical to the success of construction projects such as the FIFA stadium in Qatar, and smuggling and brokerage is intertwined with entering the country and finding work under the Kafala system (Renkiewicz, 2016). The infrastructure of smuggling stretches all the way from the villages of migrants right up to companies in the destination country. It encompasses a range of formal and informal institutions and individuals, including village-level brokers, recruitment agencies, travel agents, medical testing centres, training centres, border officials and airline staff (Abrar et al., 2017; Deshingkar et al., 2019). 
Village-level brokers fulfil several functions; they may act as a guarantor for money lenders so that migrants can obtain loans to finance their migration (Rahman, 2012), which are offered at usurious interest rates of between 30-60\% (Jureidini, 2014). Others borrow from relatives or sell family assets. Brokers may also help the migrant choose an appropriate destination based on their market intelligence. Abrar et al.'s (2017) research shows that brokers also select and channel migrants into particular jobs and help them choose a "bhalo" or good visa which could be an irregular "azad" or free visa. An Azad visa is one that is bought from a legally registered kafeel, or sponsor, by a broker to sell on to a migrant, their family, or another intermediary. Such a visa allows a migrant to enter the country as a worker tied to this particular kafeel, but in practice they can work for anybody. Such kafeels can include companies in Qatar that have unused visas which they sell to agents. There are an estimated 400,000 irregular Bangladeshi migrants in Qatar, and most have entered the country on these so called azad or free visas (Momen and Deshingkar, 2020; Jureidini, 2014: 87).

The free visa system is widespread in the Qatari construction industry. The process of recruiting workers starts with the village-level dalal or broker who takes a large lump sum from the migrant and offers them a "package." This consists of help with obtaining a passport, checking the authenticity of the visa, helping them to mobilise any other documents that are needed, and linking them up to their chosen registered recruitment agency (RA) in a major city like Dhaka. Brokers play a role in both official migration as well as irregular migration. In the former, they help the migrant to complete the formalities, and in the latter they manage the process with an azad visa, which involves linking up known RAs who have bribed contacts in key institutions like medical testing centres and passport offices as well as aviation personnel and border officials. The average price of a free visa in 2017 was QAR 25,000 (about USD 6867).

The context of female irregular migration in Bangladesh is similar to Ghana and Myanmar: the country had introduced a series of restrictions on women's migration, but these were progressively relaxed, resulting in an increase in the number of female migrants. However, women's ability to migrate internationally continues to be shaped by numerous religious, cultural and political barriers that they must negotiate, and this can explain why their numbers have remained low (Belanger and Rahman, 2013). Afsar's study among Gulf returnees in Bangladesh noted that there were no female migrants from the conservative Noakhali and Sylhet areas. Like Ghana, international migration among women is higher in the capital city of Dhaka and its surrounding areas where gender norms are more relaxed (Afsar, 2009; Siddiqui, 2002). Migration to the Gulf is an important route out of a socially constrained situation for divorced, separated and widowed women. In Afsar's sample, half the women were divorced, abandoned or widowed. Others belonged to extremely poor families with no cultivable land and were migrating to escape debt and domestic abuse.

Even there are no restrictions on women's migration, there is evidence of irregular border crossings and the prevalence of the azad visa system in this kind of migration too. Up to 45,000 Bangladeshi women had migrated to the Gulf countries between 1998 and 2011 (Rahman, 2012). Nasra Shah and Lubna Al-Kazi's research on irregular migration in Kuwait shows that relatives can buy azad visas from Kafeels and send them directly to women in Bangladesh (Shah and Al-Kazi, 2017). Another route was fake or "gala kata" visas (Afsar, 2009). In Afsar's study of brokerage in Bangladesh, a majority of women used the services of brokers to complete travel formalities (e.g., medical check-up, visa processing and flight arrangements). The broker would procure "gala kata" visas and forged passports with the help of local government officials and printing machine operators. Passage for the migrant in possession of the fake documents would be assured through the broker's network with airline staff both in Bangladesh and the destination country (Afsar, 2009). 
There is no doubt that the Kafala system was important in creating the conditions for smuggling and irregularity to flourish. However, there is also evidence of irregularity being mobilised by migrants for their own ends. Some of the women in Shah and Al-Kazi's study did not renew their work permits and remained irregularly in Kuwait for years, even decades. During their stay, they remitted significant sums back to dependents in Bangladesh, and some succeeded in paying for the higher education of their children (Shah and Al-Kazi, 2017).

\section{Conclusion}

The research synthesised in this chapter shows that smuggling arrangements are far more complex than policy narratives suggest. A multitude of arrangements can exist even in the same geographical region: often there are separate infrastructures of smuggling for men and women because they are heading to different destinations and occupations. Human smugglers offer a wide range of services for migrants including advice on routes and destinations, protection during the journey, documentation and transportation across borders.

The hardship that migrants experience while being smuggled needs to be understood with an appreciation of their goals for the advancement of their families and themselves. Smuggled migrants can and do remit significant amounts of money which is critical for improving the family's standard of living, educating siblings, investing in durable assets and repaying family debts.

In today's globalised world, interconnected by new technologies and modes of travel, the demand for cheap labour in rich countries has drawn migrants from poor countries with limited opportunities. These globalised labour regimes intersect with infrastructures of smuggling which perpetuate power asymmetries and gender inequalities by channeling particular ethnicities and nationalities into certain kinds of work. These processes contribute to the production of highly gendered and racialised patterns of migration and labour circulation.

Conversely, the infrastructures of smuggling help to expand migrant agency by giving people more choices. However, the process remains arbitrary, as there is an unpredictable mix of how "good" the smuggler is, how bribeable the border officials and police are, how much money the migrant can mobilise and, crucially, luck and chance. As human smuggling is by definition outside the purview of the law, there is no way of enforcing standards related to the treatment of migrants, costs, modes of transport, housing of migrants along the way and their reception in destination countries. In such a lawless and arbitrary process where migrants are away from their usual support networks, the smuggler has a great degree of power over migrants.

The experiences described here show that migrants' relationship with smugglers is complex. Smugglers play an ambiguous role as they are embedded in processes that reproduce structural inequalities such as the employment of undocumented migrants in highly exploitative work; at the same time, they are instrumental in opening up opportunities for marginalised communities who would otherwise have no access to international labour markets and higher wages that can be transformative for the individuals involved and the families left behind. It must be borne in mind, however, that common to all scenarios was the prevalence of informal employment arrangements without official contracts. Furthermore, the combination of state policies to combat human smuggling, trafficking and irregular migration with the constant threat of criminalisation and deportation creates insecure working and living conditions where migrant workers must accept exploitative work in order to survive, save and remit money.

In sum, this chapter provides a much-needed nuanced picture of what migration actually involves for millions of people who have been denied the right to legal and free mobility within 
the developing world. Smugglers transcend political borders and provide a critical link that connects those who have been excluded by global development with some of its gains, albeit in a highly unequal fashion. These studies on South-South smuggling are important for gaining an understanding of the relationship between poverty and the ability to migrate. Smugglers can make migration a possibility even for the very poor and those without formal educational qualifications, and help them to access international migration which is usually the preserve of the rich.

\section{Notes}

1 Migration becomes "undocumented" or "irregular" in policy parlance, when it occurs outside the legal and regulatory frameworks of the sending, transit, and destination countries. Irregular migration includes other possibilities such as remaining in the country without a visa; working in contravention of work restrictions and remaining in the country after the visa expires. Human smuggling facilitates one form of irregular migration which is crossing a border illegally with the use of falsified documents or without documents or entering a country at points other than officially sanctioned ports of entry. The term smuggling as it is used here encompasses processes that enable the illegal crossing of borders including the use of clandestine routes, bribing border officials and the falsification of travel and identity documents.

2 I use the term "migration" as an all-encompassing term to indicate mixed migration flows including economic migrants, refugees and other categories of forced migrants as their journeys may change from one form to another over the course of the journey.

3 The material is drawn heavily from research carried out under the DFID funded Migrating out of Poverty Consortium (MOOP), a ten-year programme of multidisciplinary research across Asia, Africa and the Middle East with a focus on the migration industry in the Global South.

4 http://documents1.worldbank.org/curated/en/336541505459269020/pdf/119753-PN-P133833-PUBLICGhana-Policy-Note-Ag-Sector-Review.pdf.

http://documents1.worldbank.org/curated/en/829581512375610375/pdf/121822-REVISED-PovertyReport PartEng.pdf.

https://www.worldbank.org/en/results/2016/10/07/bangladesh-growing-economy-through-advances-inagriculture\#: :text=More $\% 20$ than $\% 2070 \% 20$ percent $\% 20$ of,least $\% 20$ part $\% 20$ of $\% 20$ their $\% 20$ income.

5 For other differences please refer to https://www.unodc.org/e4j/en/tip-and-som/module-11/keyissues/differences-and-commonalities.html.

6 The Kafala system is now being reformed but the effects of that were not evident at the time of data collection.

\section{References}

Abrar, C., Deshingkar, P., Taslima Sultana, M., Haque, K.N.H., Reza, M., 2017. Emic perspectives on brokering international migration for construction from Bangladesh to Qatar. Working paper 49, Migrating Out of Poverty. University of Sussex, U.K.

Adugna, F., Deshingkar, P., Atnafu, A., 2021. Human smuggling from Wollo, Ethiopia to Saudi Arabia: Askoblay criminals or enablers of dreams? Public Anthropol. 3, 32-55.

Adugna, F., Deshingkar, P., Ayalew, T., 2019. Brokers, migrants and the state: Berri Kefach "door openers" in Ethiopian clandestine migration to South Africa. Working paper 56. Migrating Out of Poverty. University of Sussex, U.K.

Afsar, R., 2009. Unravelling the vicious cycle of recruitment: Labour migration from Bangladesh to the Gulf States. ILO.

Åkesson, L., Alpes, J., 2019. What is a legitimate mobility manager? Juxtaposing migration brokers with the EU. J. Ethn. Migr. Stud. 45, 2689-2705.

Akyeampong, E., 2000. Africans in the diaspora: The diaspora and Africa. Afr. Affairs. 99(395), 183-215.

Alpes, M.J., 2017. Why aspiring migrants trust migration brokers: The moral economy of departure in Anglophone Cameroon. J. Int. Afr. Inst. 87, 304-321. 
Anderson, B., Anderson, B.L., 2000. Doing the dirty work?: The global politics of domestic labour. Palgrave Macmillan.

Aronowitz, A.A., 2001. Smuggling and trafficking in human beings: The phenomenon, the markets that drive it and the organisations that promote it. Eur. J. Crim. Policy Res. 9, 163-195.

Awumbila, M., Deshingkar, P., Kandilige, L., Teye, J.K., Setrana, M., 2019a. Please, thank you and sorry-brokering migration and constructing identities for domestic work in Ghana. J. Ethn. Migr. Stud. $45,2655-2671$.

Awumbila, M., Teye, J.K., Kandilige, L., Nikoi, E., Deshingkar, P., 2019b. Connection men, pushers and migrant trajectories: Examining the dynamics of the migration industry in Ghana and along routes into Europe and the Gulf States. Working paper 65. Migrating Out of Poverty. University of Sussex, U.K.

Awumbila, M., Torvikeh, G.D., 2018. Women on the move: A historical analysis of female migration in Ghana, in: Migration in a Globalizing World: Perspectives from Ghana. Sub-Saharan Publishers, pp. 171-189.

Ayalew Mengiste, T., 2018. Refugee protections from below: Smuggling in the Eritrea-Ethiopia context. Ann. Am. Acad. Pol. Soc. Sci. 676, 57-76.

Ayalew, T., Adugna, F., Deshingkar, P., 2018. Social embeddedness of human smuggling in East Africa: Brokering Ethiopian migration to Sudan. Afr. Hum. Mobil. Rev. 4, 1333-1358.

Balcaite, I., 2019. Brokered (Il) legality: Co-producing the Status of Migrants from Myanmar to Thailand, in: The Migration Industry in Asia: Brokerage, Gender and Precarity. Palgrave Macmillan, pp. 33-58.

Belanger, D., Rahman, M., 2013. Migrating against all the odds: International labour migration of Bangladeshi women. Curr. Sociol. 61, 356-373.

Bredeloup, S., Pliez, O., 2011. The Libyan migration corridor. Improving EU and Us Immigration Systems. Paper prepared for the European project. European University Institute.

Bisong, A., 2020. Regional solutions: Regulating recruitment and protection of African migrant workers in the gulf and the middle east. The European Centre for Development Policy Management.

Buckley, M., Zendel, A., Biggar, J., Frederiksen, L., Wells, J., 2016. Migrant work \& employment in the construction sector. International Labour Organisation.

BWI, 2006. Defending workers rights in construction. Building and Woodworkers International.

Carden, M.R.J., 2014. Smuggling of Female Migrant Workers from Myanmar to Thailand. Master of Arts thesis, Chulalongkorn University. https://cuir.car.chula.ac.th/dspace/bitstream/123456789/44 685/1/5681215924.pdf

Carling, J., 2016. West and Central Africa. Migrant smuggling data and research: A global review of the emerging evidence base. International Organization for Migration. 25-53.

Darkwah, A.K., Thorsen, D., Boateng, D.A., Teye, J.K., 2019. Good for Parents but Bad for Wives: Migration as a Contested Model of Success in Contemporary Ghana. Working paper 61. Migrating Out of Poverty. University of Sussex, U.K.

Deshingkar, P., 2021. Criminalisation of migration for domestic work from Myanmar to Singapore-need for a radical policy shift. Eur. J. Crim. Policy Res. 1-15. https://doi.org/10.1007/s10610-020-09477-w

Deshingkar, P., Awumbila, M., Teye, J.K., 2019. Victims of trafficking and modern slavery or agents of change? Migrants, brokers, and the state in Ghana and Myanmar. J. Br. Acad. 7, 77-106.

Deshingkar, P., Zeitlyn, B., 2015. South-South migration for domestic work and poverty. Geogr. Compass. 9, 169-179.

Fernandez, B., 2019. Ethiopian migrant domestic workers: migrant agency and social change. Springer.

Fernandez, B., 2013. Traffickers, brokers, employment agents, and social networks: The regulation of intermediaries in the migration of Ethiopian domestic workers to the Middle East. Int. Migr. Rev. 47, 814-843.

Fong, E., Yeoh, B. S. A., 2020. Migrant domestic workers: disadvantaged work, social support, and collective strategies in East Asia. Am. Behav. Sci. 64, 703-708.

Franck, A.K., Arellano, E.B., Anderson, J.T., 2018. Navigating migrant trajectories through private actors: Burmese labour migration to Malaysia. Eur. J. East Asian Stud. 17, 55-82.

Gamburd, M.R., 2000. The kitchen spoon's handle: Transnationalism and Sri Lanka's migrant housemaids. Cornell University Press.

Griffiths, M., Ito, M., 2016. Migration in Myanmar: Perspectives from current research. Social policy and Poverty Research Group.

Huijsmans, R., 2014. 19 Gender, masculinity, and safety in the changing Lao-Thai migration landscape, in: Migration, Gender and Social Justice. Springer, pp. 333-349.

ILO, 2001. The construction industry in the twenty-first century: Its image, employment prospects and skill requirements. International Labour Organisation. 
Jureidini, R., 2017. Irregular migration in Qatar: The role of legislation, policies, and practices. Ski. Surviv. Irregul. Migr. Gulf. 135.

Jureidini, R., 2014. Migrant labour recruitment to Qatar. Bloomsbury Qatar Foundation Journals.

Kandilige, L., Hamidou, M.N., 2019. Migrants in countries in crisis: The Experiences of Ghanaian and Nigerien migrants during the Libyan Crisis of 2011. Afr. Human Mob. Rev. 5(2).

Kleist, N., 2017. Disrupted migration projects: The moral economy of involuntary return to Ghana from Libya. Africa. 87(2), 322-342.

Kusakabe, K., Pearson, R., 2015. Remittances and women's agency: Managing networks of obligation among Burmese migrant workers in Thailand, in: Transnational Labour Migration, Remittances and the Changing Family in Asia. Springer, pp. 50-81.

Lewis, H., Dwyer, P., Hodkinson, S., Waite, L., 2015. Hyper-precarious lives: Migrants, work and forced labour in the Global North. Prog. Hum. Geogr. 39, 580-600.

Lindquist, J., 2012. The elementary school teacher, the thug and his grandmother: Informal brokers and transnational migration from Indonesia. Pac. Aff. 85, 69-89.

Lindquist, J., Xiang, B., Yeoh, B.S., 2012. Opening the black box of migration: Brokers, the organization of transnational mobility and the changing political economy in Asia. Pac. Aff. 85, 7-19.

Mahdavi, P., 2013. Gender, labour and the law: The nexus of domestic work, human trafficking and the informal economy in the United Arab Emirates. Glob. Netw. 13, 425-440.

Meyer, S.R., Robinson, W.C., Abshir, N., Mar, A.A., Decker, M.R., 2015. Trafficking, exploitation and migration on the Thailand-Burma border: A qualitative study. Int. Migr. 53, 37-50.

Molenaar, F., 2017. Irregular migration and human smuggling networks in Niger. Clingendael CRU Rep. Febr.

Momen, L., Deshingkar, P., 2020. Hyper-precarious lives: Bangladeshi migrants on Azad visas in Qatar during the COVID-19 pandemic. https://www.routedmagazine.com/bangladeshi-azad-qatar

Osella, F., 2014. The (im) morality of mediation and patronage in south India 16 and the Gulf, in: Patronage as Politics in South Asia. Cambridge University Press. pp. 365-394.

Palmary, I., de Gruchy, T., 2016. How unpopular policies are made: Policy making for migrant women in South Africa, Bangladesh and Singapore. Working Paper 45, Migrating Out of Poverty. University of Sussex, U.K.

Parreñas, R., 2015. Servants of globalization: Migration and domestic work. Stanford University Press.

Pearson, D.R., Kusakabe, K., 2012. Thailand's hidden workforce: Burmese migrant women factory workers. Zed Books Ltd.

Platt, M., Baey, G., Yeoh, B.S., Khoo, C.Y., Lam, T., 2017. Debt, precarity and gender: Male and female temporary labour migrants in Singapore. J. Ethn. Migr. Stud. 43, 119-136.

Platt, M., Davies, S.G., Bennett, L.R., 2018. Contestations of gender, sexuality and morality in contemporary Indonesia. Asian Studies Review. Special Issue 1, 1-15.

Rahman, A., 2020. A Study on irregular migration from Bangladesh to Malaysia through the Bay of Bengal and the Andaman Sea. Otoritas J. Ilmu Pemerintah. 10, 120-131.

Rahman, M.M., 2012. Bangladeshi labour migration to the Gulf States: Patterns of recruitment and processes. Can. J. Dev. Stud. Can. Détudes Dév. 33, 214-230.

Renkiewicz, P., 2016. Sweat makes the green grass grow: The precarious future of quatar's migrant workers in the run up to the 2022 FIFA World Cup Under the Kafala System and recommendations for effective reform. Am. Univ. Law Rev. 65, 8.

Sanchez, G., 2018. Five misconceptions about migrant smuggling. Policy Brief, European University Institute, Issue 07.

Sanchez, G., 2017. Critical perspectives on clandestine migration facilitation: An overview of migrant smuggling research. J. Migr. Hum. Secur. 5, 9-27.

Shah, N.M., Al-Kazi, L., 2017. Irregular migration to and within Kuwait: Enabling and sustaining factors, in: Skilful Survivals: Irregular Migration to the Gulf. European University Institute.

Siddiqui, T., Bhuiyan, R.A., 2013. Emergency return of Bangladeshi migrants from Libya. S. Rajaratnam School of International Studies, NTS Working Paper Series, 9.

Strauss, K., McGrath, S., 2017. Temporary migration, precarious employment and unfree labour relations: Exploring the 'continuum of exploitation' in Canada's Temporary Foreign Worker Program. Geoforum. 78, 199-208.

Teye, J.K., Awumbila, M., Benneh, Y., 2015. Intra-regional migration in the ECOWAS region: Trends and emerging challenges. Migration and Civil Society as Development Drivers - a Regional Perspective. Centre for European Integration Studies. 97-123. 


\section{Priya Deshingkar}

Testaverde, M., Moroz, H., Hollweg, C.H., Schmillen, A., 2017. Migrating to opportunity: Overcoming barriers to labor mobility in Southeast Asia. World Bank.

Thu, S., Ko, K., 2015. Myth and reality in irregular migration from Myanmar. MA dissertation. Victoria University of Wellington.

Tonah, S., Codjoe, E., 2020. Risking it all: Irregular migration from Ghana through Libya to Europe and its impact on the left-behind family members. Global Processes of Flight and Migration. Göttingen University Press. 25-40.

Triandafyllidou, A., Bartolini, L., 2020. Irregular migration and irregular work: A chicken and egg dilemma, in: Migrants with Irregular Status in Europe. Springer, pp. 139-163.

Wahab, A.A., 2018. The colours of exploitation: Smuggling of Rohingyas from Myanmar to Malaysia (Warna-Warni Eksploitasi: Penyeludupan Rohingya dari Myanmar ke Malaysia). Akademika. 88, 5-16.

Yeates, N., 2012. Global care chains: A state-of-the-art review and future directions in care transnationalization research. Glob. Netw. 12, 135-154.

Zeitlyn, B., Deshingkar, P., Holtom, B., 2014. Internal and Regional Migration for Construction Work: A Research Agenda. Working paper 14, Migrating Out of Poverty, University of Sussex. U.K. 